\title{
ПРЕДПРИНИМАТЕЛЬСТВО: СОЦИАЛЬНЫЕ ФУНКЦИИ, ОСОБЕННОСТИ ДЕЯТЕЛЬНОСТИ И ПСИХОЛОГИЧЕСКИЕ ДЕТЕРМИНАНТЫ УСПЕШНОСТИ
}

\author{
Г.Н. СОЛНЦЕВА
}

\author{
${ }^{a}$ Московский государственный университет имени М.В. Ломоносова, 119991, Россия, Москва, \\ Ленинские горы, 1
}

\section{Резюме}

Перспективы развития предпринимательства в России как экономического явления обусловлены как объективными причинами, так и социально-психологической и индивидуально-личностной готовностью к предпринимательской деятельности. Психологический анализ источников продуктивной деятельности базируется на выделении основной внешней функции предпринимательства и ее форм - интенсивного и экстенсивного развития, а также внутренней функции - управления организацией. Аргументируется необходимость такой дифференциации функций для выявления особенностей деятельности и личности предпринимателей малого и крупного бизнеса. Систематизированы теоретические представления и эмпирические данные об условиях и особенностях деятельности, психологических характеристиках предпринимателей малого и крупного бизнеса, а также менеджеров среднего и высшего уровней управления. Ведущей характеристикой деятельности предпринимателей признается новаторство, проявляющееся в появлении и реализации новых общественно значимых целей, новых средств достижения известных целей. Отмечается, что новаторство в малом и крупном бизнесе характеризуется различными механизмами. Для крупных фирм характерно предпринимательское управление, нацеленное на организационные преобразования и принятие решений на всех уровнях сложных иерархических систем, повышающие устойчивость и конкурентоспособность организации. Принятие решений характеризуется взвешенностью, риски оценены и невелики. Для малого бизнеса новаторство приобретает вид более основательных изменений для обеспечения выживания и развития - риски велики и трудно поддаются управлению в силу ограниченности ресурсов. В силу отмеченных различий следует ожидать различий индивидуально-личностных особенностей предпринимателей крупного и мелкого бизнеса, детерминирующих успешность деятельности. Эмпирическое исследование в явном виде не выявило отличий предпринимателей малого и крупного бизнеса, что связано с реальностью: малый бизнес сегодня обеспечивает в основном расширение ресурсов общества, доля инновационных предприятий мала, доступными оказались лишь предприниматели без признаков инноваций в сферах торговли, связи и мелкого производства. Результаты диагностики индивидуальноличностных характеристик предпринимателей и менеджеров подтвердили приоритет мотивации достижения у предпринимателей, проявляющейся в склонности к риску, а также выявили особенности отдельных характеристик интеллекта и коммуникативных процессов для успешности предпринимательства. Однако нет достаточных оснований для отказа от идеи дифференциации предпринимательства по форме реализации функции развития, как и поиска основной детерминанты или системы детерминант внутреннего стремления к преобразующей деятельности - основной характеристики предпринимателя.

Ключевые слова: предпринимательство, условия и содержание предпринимательской деятельности, индивидуально-личностные качества успешного предпринимателя, мотивация достижения, склонность к риску, интеллект, система ценностей, коммуникация. 


\section{Функции и условия предпринимательства}

Социально-экономическое развитие общества в целом, отдельных его структурных составляющих и форм управления предполагает преодоление разрыва (несоответствия) между уровнем и темпом научных разработок и социально-экономическими условиями их практической реализации, между сложившимися и новыми научно обоснованными технологиями организации различных сфер жизни общества. Сложившиеся организационные структуры характеризуются высокой степенью устойчивости и, как следствие, низким уровнем изменчивости и несоответствия результатов их функционирования ожиданиям общества при изменении условий. Необходимы определенные условия и усилия для объединения имеющихся социально-экономических ресурсов в новые и уникальные комбинации, что не только обеспечивает полноту их использования, но и становится движущей силой реорганизаций и социальных перемен в обществе (Шумпетер, 2008). В современных условиях основной вектор развития связываются с предпринимательской деятельностью. Предпринимательство - целесообразная деятельность, включающая создание, развитие и руководство организацией как совокупностью ресурсов, капитала, информации и труда, ориентированных на получение прибыли в конкретных экономических, политических и социальных условиях. Эта особого рода трудовая (с целью получения прибыли) инновационная деятельность управления в хозяйственной сфере характеризуется самостоятельным принятием решений и личной ответственностью за результаты хозяйствования.

Ключевыми для определения предпринимательства являются отношение к ресурсам и наличие нововведений. Предпринимательство характеризуется частным (акционерным) владением предприятием (ресурсами) в отличие от индивидуального владения или наемного труда (Заславская, 1995). При этом предпринимательство - это 1) не «рекомбинированная» собственность как результат распоряжения государственными ресурсами и информацией и перевода государственного имущества в частную собственность (приватизации), 2) создание новой организационной единицы, а не результат перераспределения ресурсов стабильной организации в условиях корпоративной культуры и конкуренции.

Наличие нововведений в условиях собственности на ресурсы является достаточным, но не необходимым признаком предпринимательства: их отсутствие сохраняет отнесение деятельности к предпринимательству, ограничивая его функцию развития экстенсивной формой. Интенсивное развитие осуществляется за счет расширения спектра форм и способов использования имеющихся материальных и интеллектуальных ресурсов - наукоемких технологий, более совершенных форм и методов организации труда, информационного обеспечения, в противовес экстенсивному развитию - количественному приращению ресурсов без качественного их изменения с поддержанием сложившихся способов управления. Для разных условий предпринимательство обеспечивает функцию развития, но в разных формах, которые могут рассматриваться как этапы развития - экстенсивное развитие является 
необходимым условием его интенсификации. Повышение доли частных компаний, обеспечивающих расширение и обновление продуктов или услуг, ориентированных на запросы потребителя, может рассматриваться как экстенсивная форма развития - увеличение ресурсов. Темпы обновления дают компаниям конкурентное преимущество и перспективы, создают условия интенсивного развития. При достаточности ресурсов предпринимательство потенциально способно обеспечить быструю качественную перестройку хозяйственной деятельности посредством новшеств, не опробованных реальной практикой и отличающихся от традиционно используемых способов деятельности. Изменяется организация рабочих групп - расширяется практика организации многофункциональных и автономных команд, виртуальных офисов и сетевых компаний, что отражается на изменении содержания и особенностей профессиональной деятельности различных сфер (фон Мизес, 2012).

Объективными условиями предпринимательской деятельности, описывающими возможности ее осуществления, являются три группы характеристик: 1) уровень развития и объем материальных и экономических ресурсов (ограниченность объема и доступности ресурсов не позволяют их «комбинировать» и достигать лучших результатов); 2) технологичность общества - уровень развития науки и технологий, обеспечивающий «базис» новых средств и способов организации хозяйственной жизни; 3) социальные условия предпринимательства - объективные политические и экономические условия, характеризующие «готовность» общества к принятию новых форм отношений. В частности, к социальным условиям относятся изменения правовых основ экономической деятельности, элементов корпоративной и предпринимательской культуры, системы ценностей общества, формирующие отношение к индивидуальной инициативе и регулирующие инновационные процессы.

Связь объективных условий предпринимательства носит преобразующий детерминированный характер: характеристики (наличие или ограниченность) ресурсов преобразуют оценку их функциональности и ориентируют либо на их наращивание, либо на новые более эффективные формы их использования, интенсифицируя изменения технологических условий. Предпринимательство способно обеспечить как увеличение ресурсов при их ограниченности, так и их использование в новых комбинациях, оно является функциональным органом экстенсивного и интенсивного развития организационных систем и общества.

Отсутствие объективных условий делает невозможной предпринимательскую деятельность, однако при благоприятных условиях необходимы субъективные условия - психологическая готовность, индивидуально-личностные характеристики, определяющие выбор предпринимательской деятельности и ее успешное осуществление. Именно субъективные переменные детерминируют инициативную, самостоятельную активность, осуществляемую от своего имени, на свой риск и под свою имущественную ответственность, - предпринимательскую деятельность.

Создание условий для предпринимательства является одной из приоритетных задач социально-экономического развития России, мощным ресурсом 
экономических преобразований, а их характер может рассматриваться в качестве индикатора успешности и глубины проведения экономических реформ. Становление предпринимательства пришлось на эпоху новых технологий, что характеризует достаточность технологических условий его развития. Преобладание корпоративной культуры в мировом хозяйстве, изменения существующей экономической и политической систем инициируют предпринимательство, а наряду с динамикой роста положительного отношения к предпринимательству обеспечивают социальные условия его развития.

Важным условием развития предпринимательства является готовность субъекта к деятельности. Во все времена и во всех сферах жизни общества существовала категория людей, стремящихся выйти за рамки сложившихся форм организации, прогнозировать и удовлетворять (часто и формировать) новые потребности общества, адекватно оценивать объективные условия, способных рисковать и брать на себя ответственность за результаты своей активности. Выявление особенностей деятельности и качеств предпринимателей основная цель психологических исследований, достижение которой позволит оптимизировать соотношение внешних объективных условий и психологических ресурсов (устремлений и возможностей) предпринимателей, соотношение субъективных целей и социально значимых функций для общества.

\section{Особенности предпринимательской деятельности}

Предпринимательство официально признано трудовой деятельностью и включено в законодательно-правовую систему, поскольку характеризуется всеми ее признаками: выполняет социально значимую функцию, направлено на социально значимый результат, характеризуется осознанием обязательности достижения цели, необходимости совместных действий, сознательным выбором средств и способов деятельности. При этом предпринимательская деятельность по ряду параметров не приобрела статуса профессии: неоднозначно определение ее социальных функций, отсутствуют стандарты ее реализации, противоречивы представления о предпринимателях как социальной группе, о требуемых индивидуально-личностных качествах и компетенциях (Александрова, 2000).

Предпринимательство в системе разделения труда относится к управленческой деятельности, имеет аналогичную структуру и общие черты. Общими для предпринимательской и управленческой деятельности являются следующие характеристики: 1) менеджмент и предпринимательство не рассматриваются как отрасль и характеризуют все сферы экономики, а субъекты могут легко переходить из одного сектора в другой; 2) объектом управления является социотехническая система, что отражается на разнообразии задач, прерывистости и фрагментарности процесса в отличие от повторяющегося, непрерывного, устойчивого характера действий и операций управления материальными объектами; 3) тождественность функций управления (планирование, организация, контроль и регулирование) и их психологическая реализация в ходе межличностного и информационного взаимодействия за счет процессов 
коммуникации и принятия решения (Геберт, фон Розенштиль, 2006; Кабаченко, 2000; Мескон и др., 2007); 4) решающим в обеспечении эффективности управления является психологический фактор - совокупность способностей, сопряженных с особенностями опыта и мотивации.

Основные отличия деятельности предпринимателя связаны с ограниченностью и часто невозможностью стандартизации и алгоритмизации предпринимательской деятельности, содержание которой интегрирует своеобразие ее условий и факторов при идентичности формальных признаков управленческих функций (фон Мизес, 2012). При этом необходимо учитывать особенности этапа развития организации, поскольку на различных стадиях предприниматель имеет разные цели и задачи, реализует различные функции (Троицкая, 2010; Хизрич, Питерс, 1992). К общим особенностям в различных сферах предпринимательской деятельности (производственной, коммерческой, финансовой и сфере потребления) относятся высокая динамичность, неопределенность, отсутствие регламентов, наличие множества рисков, возникающих в процессе реализации деятельности (Асаул, 2009). Особенности деятельности предпринимателя связываются также с ограниченностью времени планирования, организационных процессов, но в основном времени на принятие решений.

Особенности предпринимательства как управления обусловлены объективными характеристиками и субъективными переменными. Объективно организационные структуры в предпринимательстве имеют следующие отличия.

1. Система управления лишь отчасти имеет иерархическую структуру, включает элементы линейно-ядерных структур, проявляется в сокращении количества средних уровней и повышении значимости горизонтальных связей.

2. Относительно низкая дифференциация функций в совместной деятельности (для малого и среднего бизнеса), расширение должностных обязанностей, предписанных функций и ролей сотрудников.

3. Нормативы деятельности ограничены требованиями к результату, спектр средств и способов управления ресурсами предприятия ограничен лишь правовыми нормами.

4. Основным источником нарушения устойчивости системы управления являются внешние условия, базирующиеся на относительно стабильной системе норм и традиций.

5. Ситуации деятельности в большой степени характеризуются как динамичные, неопределенные с высокой вероятностью экстремальности.

6. Отсутствуют регламенты норм знаний, необходимых для реализации трудовой деятельности.

Предпринимательская деятельность как управление обусловлена не столько внешними обстоятельствами, сколько своеобразием качеств личности предпринимателя в условиях рыночной среды и предпринимательской культуры (Куянцев и др., 2012). Для нее характерны следующие особенности: 1) деятельность инициируется внутренней мотивацией, цели конкретизируют личностные мотивы и соотносятся с анализом ситуации и личностных возможностей, регламентируются лишь правовыми и юридическими нормами; 
2) предприниматели характеризуются широким разнообразием субъективного опыта (сфера и уровень образования, опыт практической деятельности), обусловленного своеобразием путей «вхождения» в предпринимательство, в том числе и криминальных; 3) принятие решений отличается личностными пристрастиями (критерии и ценности) и высоким уровнем личностной ответственности (Шумпетер, 2008).

Отмеченные особенности в разной степени реализуются в организациях малого и крупного бизнеса. Для малого бизнеса характерны низкая дифференциация функций в совместной деятельности, вариативность средств и способов достижения целей - субъект сам выбирает или создает их, опираясь на внутренние ресурсы; в крупном бизнесе - высокая дифференциация функций и закрепление их в нормативах организации. Все группы предпринимателей ограничены в своем опыте (имеют разную профессиональную подготовку и различный опыт работы), не ориентированы на получение специальных знаний и навыков. Ограниченность опыта преодолевается в малом бизнесе за счет собственных способностей и анализа ошибок, для крупного бизнеса характерно привлечение специалистов.

Наибольшие различия проявляются в отношении таких качественных особенностей предпринимательства, как инновационный характер и высокая степень риска. По мнению большинства исследователей, характеризует предпринимательство именно инновационность - реализация новых комбинаций условий и средств, проявляющаяся в новизне продуктов, целей, средств и способов их получения, для которых не заданы требования и которые могут оказаться уникальным и не имеющим аналогов (Агеев, 2016). Предприниматель для преодоления рыночной неопределенности ориентирован на изменение ситуации, что возможно лишь при творческом ее осмыслении и нахождении новых способов получения устойчивого рыночного преимущества. Инновации - основной инструмент предпринимателя, и успешность деятельности зависит от умения предпринимателя использовать этот инструмент (Щербатых, 2008).

Во всех видах труда присутствуют элементы новаторства, однако только в предпринимательстве новизной отличаются все составляющие деятельности - постановка целей и задач, выбор средств и способов их решения, критерии оценки результатов. Новаторство - не открытие или изобретение, а практическая реализация идеи, коммерциализация новых технических, технологических, организационных и иных достижений. Склонность к инновационной деятельности в условиях собственности на ресурсы и свободы принятия решения превращает работника в предпринимателя.

По инновационной активности имеются различия между предприятиями малого и крупного бизнеса. Для малых предприятий с ограниченными ресурсами конкурентное преимущество и выживание обеспечиваются инновациями. Крупный бизнес располагает более широкими ресурсами и тем самым имеет конкурентное преимущество и ориентирован на его сохранение, инновации касаются решения частных тактических вопросов при сохранении стратегии предприятия, ориентированной на стабилизацию организационных структур и управления. 
Неизбежным следствием инновации является осознание вероятностного характера достижения желаемого результата, а неуспех сопряжен со значительными материальными и морально-психологическими потерями (Щербатых, 2008). Высокая степень риска является второй специфической особенностью деятельности предпринимателя. При этом степень риска для малых предприятий значительно выше, чем для предприятий крупного бизнеса, которые располагают ресурсами анализа и управления рисками.

Следует заметить, что необходимым условием реализации инноваций в условиях риска признан высокий уровень «деловой активности» предпринимателя (Позняков, 2007), его внутренний потенциал. Для малого бизнеса это является решающим условием, в то время как в крупном бизнесе и потенциал, и деловая активность являются интегральной характеристикой человеческих ресурсов, в которых уровни индивидуальной активности компенсируются за счет усложнения организационной структуры и расширения ресурсов.

\section{Индивидуально-личностные особенности предпринимателя}

Успешность предпринимательской деятельности обусловлена не столько общественно значимыми функциями и социально-экономическим статусом, сколько психологическими и личностными особенностями - способностями индивида, обеспечивающими рациональное инновационное соединение факторов производства и риска (Асаул, 2009). Интегральной характеристикой субъективной сферы является предприимчивость - способность достигать конкретных целей за счет собственной инициативы, изобретательности, принятия нестандартных решений, риска и ответственности. Психологическим коррелятом предприимчивости является готовность к такой деятельности, определяющей выбор предпринимательской деятельности в качестве сферы приложения сил, реализации личностного потенциала и источника дохода. Неготовность может стать причиной неудач, личностных кризисов в силу неадекватной оценки наличных условий, особенностей деятельности и своих возможностей. Психологическая готовность предполагает выраженность у субъектов определенных качеств, обеспечивающих выбор этого типа деятельности, реализацию инноваций и готовность к неудачам (риску).

Большинство описаний особенностей предпринимателя базируются на здравом смысле. Возможность деятельности обеспечивают такие характеристики, как инициатива, острота восприятия, авторитет, интуиция, творческие способности и воображение, способность оказывать влияние на окружающих; значимыми для успеха предпринимательства признаются целеустремленность, поиск новизны и принятие риска (Лукьянов, 2002). При этом отмечается, что целеустремленность характеризует и менеджеров, однако их цели достигаются скорее в условиях соблюдения правил и стандартов организации, а деятельность направлена на поддержание стабильности и порядка внутри уже созданной структуры. Успешный предприниматель характеризуется также такими качествами, как самостоятельность (ориентация на собственный анализ и оценку текущей информации), небольшая подверженность конформным 
влияниям, а также способность прогнозировать (природный интеллект), инициативность (Журавлев, Позняков, 2012). Ряд авторов отмечают такие черты предпринимателя, как способность отделять существенное от несущественного, стремление к лидерству, самостоятельность и ответственность, независимость, стрессоустойчивость, смелость и решительность, умение действовать в непривычных условиях и при отсутствии правил принятия решений. Имеются данные о таких особенностях предпринимателей, как готовность к энергозатратам (труду и расширению знаний), чувствительность к новизне, развитый внутренний контроль, способность в трудных ситуациях соседствовать с проблемой и строить ситуацию по-новому, сдержанность и требовательность в оценке результатов деятельности, устойчивость к внешним воздействиям (помехам), оптимизм (Тутушкина, 2001).

Описание особенностей предпринимателя не отличается определенностью в силу «размытости» используемых понятий. По концептуальной обоснованности индивидуально-личностных характеристик предпринимателя более конструктивным представляется выделение блоков психических особенностей, соответствующих структурным составляющим деятельности. С позиции рассмотрения предпринимательства как управления индивидуально-личностные особенности обусловлены своеобразием основных процессов - принятия решения и коммуникации, с позиции функциональной структуры деятельности - инвариантными характеристиками мотивационно-волевой, интеллектуальной и коммуникативной (Дейнека, 2006) или когнитивной, мотивационной и регулятивной (Волков и др., 1987) составляющих деятельности. Отметим, что содержание, особенности опыта и операциональных схем (стратегии и тактики) обусловлены спецификой основных компонентов психической системы вне зависимости от концептуальной позиции.

Особенности мотиващии предпринимателей однозначно интерпретируются в рамках различных подходов и теорий. Описание источников мотивации - внешняя или внутренняя - предполагает, что предприниматели характеризуются преимущественно внутренней мотивацией, обусловленной познавательными потребностями и уровнем активности. При внешней мотивации вряд ли стоит ожидать высокой активности и ориентации на преодоление стереотипов оценки ситуаций и действий в них.

Мотивы деятельности предпринимателей не отличаются по составу от мотивов других видов трудовой деятельности. По мнению большинства исследователей, основными являются экономические мотивы - получение дохода, извлечение прибыли. Деньги (доход) - критерий успеха, который приобретает характер знака деловой репутации предпринимателя, его социальной значимости и признания в обществе. Экономические мотивы могут рассматриваться как системообразующий фактор ценностей, отражающих приоритеты в структуре мотивации: мотивы социальной природы (признания, независимости и самореализации) являются, по-видимому, равнозначными; наибольшую ценность, по результатам ряда исследований, имеет семья - благополучие и будущее детей, здоровье (свое и родных).

Теоретически обоснованы и эмпирически проверены различия видов мотивации - ориентированной на достижение (успех) или избегание неудач 
(Макклелланд, 2007). Для предпринимателя характерны однозначная ориентация на успех и уверенность в нем. Успехи воодушевляют его, удовлетворение от достигнутого результата приводит к стойкому положительному отношению к деятельности и ориентации на новые достижения. В случае неудач субъект преимущественно не отказывается от новых попыток, способен к новому взгляду на ситуацию и новым решениям, новым способам достижения желаемого результата. Эмпирически подтверждена связь высокого уровня мотивации достижения и способностей к переосмыслению ситуаций и поиску новых решений (Murray, 1943), что соответствует представлениям об успешном предпринимателе. При мотивации избегания неудач предприниматель вряд ли способен к новым попыткам и новым решениям. Именно мотивация достижения может рассматриваться как условие предпринимательской деятельности и основное качество успешного предпринимателя.

Для предпринимателей характерна наименьшая семантическая разница между понятиями «успех» и «неудача» в силу того, что и успех и неудача оцениваются как соответствие результата действий внутреннему потенциалу и выбранной стратегии его достижения. Такая семантическая близость свидетельствует о высоком уровне внутреннего контроля и выраженности в большей мере качеств интроверсии, чем экстраверсии. Реакция на неудачу может рассматриваться как закономерное проявление мотивации достижения: предприниматель в такой ситуации оказывается способным, по терминологии К. Марбе, к «переключению» с анализа причин и условий неудачи на достижение цели (см.: Котик, 1989). Отношение к успеху (неудачам) может рассматриваться как проявление личностной регуляции, обусловленной высокими уровнями самоценки, притязаний, субъективного контроля и рефлексии.

В исследованиях управленческой деятельности Р. Блейк выявил характеристику направленности мотивации - на дело (результат) или на людей (отношения) (см.: Стрелков, 2005). Наиболее вероятно, что предприниматели ориентируются преимущественно на дело, собственный успех. Хотя нет прямых данных о такой направленности в деятельности предпринимателей, косвенными аргументами правомерности такого предположения являются особенности системы ценностей, приоритетами которой являются личное благополучие и благополучие семьи, стремление к самореализации.

Особенности мотивации в условиях неопределенности и принятия решения проявляются в отношении к риску. Предприниматель постоянно нацелен на поиск решений, превращающих рыночную нестабильность и неопределенность в устойчивость дохода. Для предпринимателя нет гарантий успеха, как и нет источников возмещения потерь в случае неудачи, что составляет суть его экономических рисков; он принимает на себя ответственность за результаты деятельности, готов пережить неудачи в процессе экономической деятельности (Щербатых, 2008). В современной отечественной хозяйственной практике такие понятия, как риск, нестабильность, неопределенность, уровень риска, а также управление рисками, законодательно закреплены и стали обязательной составляющей любого бизнес-плана. 
Предпринимательский риск основан на оценке ситуации, расчете и учете всех возможных отрицательных последствий. Стремление к успеху уравновешивается ответственностью, степень которой в значительной мере определяет приемлемый для предпринимателя уровень риска - снижение дохода, убытки, потеря собственности. Предприниматель в явном виде проявляет склонность рисковать, принимать условия риска и готовность действовать, которые приобретают статус личностных качеств и определяют успешность предпринимательской деятельности (Ильин, 2012). Оценка отношения предпринимателя к риску приобрела характер факта, который не подвергается сомнению. Склонность к риску, детерминированная мотивацией достижения и ориентацией на результат, рассматривается как необходимое условия предпринимательства и индивидуально-личностная особенность, обеспечивающая возможность деятельности, а отсутствие склонности ограничивает выбор, инициацию и успешную реализацию трудовой деятельности.

Другие характеристики мотивации, выявленные в ходе исследований реальных предпринимателей, требуют осмысления и уточнения образа «идеального» предпринимателя. Исследования особенностей мотивации российских предпринимателей свидетельствуют о ведущей роли мотивов роста благосостояния (и максимального контроля будущего), распространения стиля и образа жизни на сферу деловой активности, реализации способностей. Отмечена равнозначность ценности личного успеха и самореализации, уважения других, нравственности и достатка. Особенности познавательных мотивов в структуре мотивации в исследованиях не отмечены, требуют специального анализа. Появление новаторских идей, характеризующих предпринимательство, связано с познавательной потребностью и уровнем умственной активности. Низкий уровень познавательной активности проявляется в сужении сферы интересов (любознательности), снижении уровня когнитивной сложности: индивид воспринимает и оценивает ситуацию стандартным способом и действует по сложившимся схемам, особенно в повторяющихся ситуациях и при ограниченности внутренних ресурсов. Высокая психическая активность - необходимое условие нового взгляда на ситуации, новаторства как основной характеристики предпринимательства.

Особенности интеллектуальной (когнитивной) составляющей деятельности предпринимателей проявляются в анализе ситуации и прогнозировании ее развития, оценке альтернатив и рисков, поиске новых вариантов решения текущих задач в условиях неопределенности. Мышление выступает одновременно и как основной ресурс и средство деятельности предпринимателя, и как объект сознательного контроля. Интегрируя ментальные модели себя и ситуации, субъект «сопоставляет» их, прогнозируя изменения ситуации в зависимости от оценки собственного состояния в будущем. В таком контексте предпринимательство - интеллектуальная деятельность, субъект которой владеет дополнительным ресурсом рефлексивного контроля. Теоретически обоснованными являются преимущества предпринимателей по интеллекту, открытости опыту и рефлексивности (Дейнека, 2006), которые составляют творческий потенциал и проявляются в креативных идеях и способах их реализации. 
Для творческой оценки ситуаций и креативного решения необходимым является преобладание рационального мышления (Мухарлямова, Холуева, 2014), сопряженного с комбинаторными и прогностическими способностями и развитой интуицией. Имеются данные о своеобразии отношения к проблемным ситуациям и их решения: для предпринимателей характерно устойчивое «соседство» с проблемой, ограниченное использование стратегий компромисса, апелляции к нормам закона, конфронтации или отвержения (Тутушкина, 2001).

Процессы коммуникации признаются как наиболее значимые в управленческой деятельности наряду с принятием решения. Особенности коммуникаций предпринимателей связаны с их функциональностью в рамках решаемых вопросов и широтой контактов с наемными работниками своего предприятия, представителями государственных структур, деловыми партнерами, поставщиками, конкурентами, потребителями (Романова, 2003). При этом не обнаружены исследования, описывающие закономерности и особенности коммуникаций предпринимателей.

Сведения о личностных качествах предпринимателей ограничены и противоречивы. Можно лишь предполагать, что особенности мотивации и системы ценностей, высокий уровень внутреннего контроля позволяют отнести предпринимателей к категории интровертов с высокой самооценкой и притязаниями.

Таким образом, данные теоретического анализа и ограниченных эмпирических исследований формируют представление о психологических (индивидуально-личностных) особенностях, обеспечивающих успешность предпринимательской деятельности. Успешный предприниматель характеризуется выраженной внутренней мотивацией, направленной на успех, ориентированной на результат (а не людей). Он должен обладать интеллектуальными способностями, высоким уровнем внутреннего контроля и рефлексии, обеспечивающими принятие решения и инновации, а также способность к продуктивной коммуникации, что в совокупности определяется как организаторские способности.

Для уточнения индивидуально-личностных особенностей предпринимателей был проведен цикл пилотажных (на ограниченной выборке) исследований в рамках НИР студентов старших курсов факультета психологии МГУ. Схема исследований включала оценку значимости различий групп предпринимателей (две группы малого и крупного бизнеса в сферах торговли, услуг связи и производства) и менеджеров (две группы среднего и высшего звена финансовых, производственных и торговых предприятий); каждая группа включала 10-15 человек в силу ограниченности доступности предпринимателей и менеджеров. Переменными в исследовании были характеристики когнитивных способностей (уровень интеллекта и характеристики мышления, личностная креативность), мотивации достижения и склонности к риску, коммуникативных и организаторских способностей (эмоциональный интеллект, позиция), диагностируемых стандартными методиками.

Результаты сравнения групп менеджеров среднего и высшего звена показали, что между ними нет значимых различий по всем измерениям, однако с 
тенденцией снижения показателей мотивации достижения, когнитивной сложности, склонности к риску и эмоционального интеллекта менеджеров высшего звена. На уровне тенденции проявились различия предпринимателей малого и крупного бизнеса: владельцы малых предприятий характеризуются более выраженной мотивацией достижений, в большей степени склонны к риску, демонстрируют лабильность мышления, а также больший объем интеракций и сниженную ориентацию на личностные отношения в коммуникации. Выявленные тенденции требуют подтверждения и объяснения, например, в контексте анализа профессионального развития и деформаций.

Основные результаты в соответствии с целью связаны с установлением различий групп предпринимателей и менеджеров без уточнения их позиции в организации. Результаты свидетельствуют о достоверном преимуществе предпринимателей по показателям мотивации достижения и склонности к риску, когнитивной сложности, лабильности и любознательности при одинаковом уровне общего интеллекта.

Анализ коммуникативных и организаторских способностей показал, что при одинаково высоком уровне эмоционального интеллекта предприниматели продемонстрировали более высокий уровень коммуникативных и организаторских способностей. Предприниматели игнорируют эмоциональный фон, отличаются низким уровнем распознавания и демонстрации эмоционального отношения, в то время как коммуникации и организаторские способности менеджеров базируются на распознавании и демонстрации эмоций. Предприниматели в меньшей степени ориентированы на личностные отношения и имеют больший объем интеракций, при этом у них и в большей степени выражены общие организаторские способности; менеджеры ориентированы на личностные отношения в коммуникациях для поддержания устойчивости групп. В области контроля позиция предпринимателя - автономия и контроль деятельности других, коммуникация является средством контроля участников процесса и манипулирования; для менеджера значимыми оказываются демонстрация включенности во взаимодействие, распознавание реакции партнера в позиции контролируемого, что обусловлено ориентацией на принадлежность группе (область включенности).

Особенности коммуникации предпринимателей интерпретируются как выраженные способности быстрой адаптации в новой обстановке - установления дружеских и деловых отношений, проявления инициативы в общении и принятия решения в трудных нестандартных ситуациях, что согласуется с общими представлениями об успешных предпринимателях.

Таким образом, особенности мотивации, системы ценностей, устойчивость к неопределенности и склонность к риску, а также особенности мышления креативность, подвижность, рациональность, комбинаторные способности, базирующиеся на высокой самооценке и подкрепленные высоким уровнем рефлексии и организаторскими способностями,- являются основными психологическими условиями и факторами успешности предпринимательской деятельности. 


\section{Заключение}

Предпринимательство в социально-экономической структуре российского общества не является устоявшимся явлением. Причины выбора формы трудовой деятельности разные: вынужденные и случайные обстоятельства, использование шанса или личный выбор, обусловленный стремлением к независимости, реализации потенциала и личностного самоутверждения. В этих условиях функции предпринимательства в обществе неоднозначны: интенсивное развитие за счет инновационной деятельности и интеллектуального ресурса или экстенсивное развитие за счет количественного увеличения материальных и трудовых ресурсов. Особенности предпринимательской деятельности и личностные детерминанты успешности оказываются производными от реально выполняемой функции в системе общественных отношений. Предприниматель, характеризующийся мотивацией достижения, творческим осмыслением ситуации, склонностью к новаторству и обоснованному риску на основе рациональной критичной оценки ситуации, - идеальный образ, формируемый в соответствии с функцией интенсивного развития. В реальности доля таких предпринимателей мала, а их смешение с собственниками предприятий, выполняющих функцию экстенсивного развития, затрудняет выявление особенностей деятельности и личности предпринимателя-реформатора. Положение о различии видов предпринимательской деятельности по критерию формы общественно значимой функции (экстенсивное или интенсивное) развития не получила эмпирического подкрепления; нет различий между предпринимателями малого и крупного бизнеса. Этот результат объясняется тем, что малый бизнес сегодня в основном обеспечивает расширение ресурсов общества, доля инновационных предприятий мала, доступными оказались лишь предприниматели без признаков инноваций - в сферах торговли, связи и мелкого производства. Нет оснований для отказа от идеи дифференциации предпринимательства по форме реализации функции развития. В перспективе дифференциация может стать основой описания инновационного потенциала, а на практике - основой психологической поддержки предпринимателей - разработки специальных образовательных программ, прогнозирования успешности и коррекции в ходе профессионального консультирования, а также поддержки государственных и предпринимательских структур по оптимизации психологических условий развития малого и среднего бизнеса в России.

\section{Литература}

Агеев, А. И. (2016). Предпринимательство (4-е изд., расшир. и доп.). М.: Институт экономических стратегий/РУБИН.

Александрова, Т. Л. (2000). Методологические проблемы социологии профессий. Социологические исследования, 8, 11-17.

Асаул, А. Н. (2009). Организация предпринимательской деятельности. СПб.: АНО ИПЭВ.

Волков, А. М., Микадзе, Ю. В., Солнцева, Г. Н. (1987). Деятельность: структура и регуляция. М.: Издво Московского университета. 
Геберт, Д., фон Розенштиль, Л. (2006). Организационная психология. Человек и организащия. Харьков: Гуманитарный центр.

Дейнека, О. С. (2006). Экономическая психология. Национальньй психологический журнал, 1(1), 110-113.

Журавлев, А. Л., Позняков, В. П. (2012). Социальная психология предпринимательства. М.: Институт психологии РАН.

Заславская, Т. И. (1995). Бизнес-слой российского общества: сущность, структура, статус. Социологические исследования, 3, 3-12.

Ильин, Е. П. (2012). Психология риска. СПб.: Питер.

Кабаченко, Т. С. (2000). Психология управления. М.: Педагогическое общество России.

Котик, М. А. (1989). Психология и безопасность (3-е изд., испр. и доп.). Таллин: Валгус.

Куянцев, И. А., Галачиева, С. В., Куянцева, И. И. (2012). Роль предпринимательства в экономическом и социальном развитии общества. Terra economicus, 10(2, ч. 2), 39-42.

Лукьянов, А. С. (2002). Психологические качества предпринимателя, обеспечивающие успешность его деятельности. В кн. Психологический ресурс в экономике и предпринимательстве: Материаль Всероссийской научно-практической конференции, 23-25 октября 2002 г. (с. 175-182). Ставрополь: Северо-Кавказский социальный институт/Ставропольсервисшкола.

Макклелланд, Д. (2007). Мотивация человека. СПб.: Питер.

Мескон, М. Х., Альберт, М., Хедоури, М. (2007). Основы менеджмента. М.: Вильямс.

Мухарлямова, А. Ю., Холуева, К. А. (2014). Анализ образа предпринимателя в современном обществе. Современные проблемы науки и образования, 3, 639-647.

Позняков, В. П. (2007). Феноменология предпринимательства: синтез экономического и психологического аспектов. В кн. Д. Я. Райгородский (ред.), Психология предпринимательства. Хрестоматия (c. 3-16). М.: Бахрах-M.

Романова, Е. С. (2003). 99 популярных профессий. Психологический анализ и профессиограммы. СПб.: Питер. Стрелков, Ю. К. (2005). Инженерная и профессиональная психология. М.: Академия.

Троицкая, И. В. (2010). Психология предпринимательской деятельности и основы экономической психологии. Курс лекций. СПб.: СПбГАСУ.

Тутушкина, М. К. (ред.). (2001). Практическая психология. Учебник для вузов (4-е изд., перераб. и доп.). СПб.: Дидактика Плюс.

Фон Мизес, Л. (2012). Человеческая деятельность: трактат по экономической теории. Челябинск: Социум.

Хизрич, Р., Питерс, М. (1992). Предпринимательство, или Как завести собственное дело и добиться успеха. М.: Прогресс-Универс.

Шкаратан, М. О. (1994). Феномен предпринимателя: интерпретация понятий. В кн. В. В. Радаев (ред.), Становление нового российского предпринимательства (социально-экономический аспект) (с. 199247). М.: Институт экономики РАН.

Шумпетер, Й. (2008). Теория экономического развития. М.: Директмедиа Паблишинг.

Щербатых, Ю. В. (2008). Психология предпринимательства и бизнеса. Учебное пособие. СПб.: Питер.

Ссылки на зарубежные источники см. в разделе References после англоязычного блока.

Солнцева Галина Николаевна - доцент, факультет психологии, МГУ имени М.В. Ломоносова, кандидат психологических наук.

Сфера научных интересов: структура и регуляция деятельности, инженерная психология, рефлексивные процессы и управление, принятие решений Контакты: galinasolntseva@mail.ru 


\title{
Entrepreneurship: Social Functions, Business Features and Psychological Determinants of Success
}

\author{
G.N. Solntseva \\ ${ }^{a}$ Lomonosov Moscow State University, 1 Leninskie Gory, Moscow, 119991, Russian Federation
}

\begin{abstract}
Prospects for the development of entrepreneurship in Russia as an economic phenomenon are conditioned both by objective reasons, and by socio-psychological and individual-personal readiness for entrepreneurship. Psychological analysis of the sources of productive activity is based on the highlighting of the main external function of entrepreneurship and its forms - intensive and extensive development, as well as the internal function - the management of the organization. The need for such differentiation of functions to identify the characteristics of the activities and personality of small and major entrepreneurs is discussed. Theoretical representations and empirical data on the conditions and features of the activity, psychological characteristics of small and major entrepreneurs, as well as managers of middle and higher levels of management are systematized. Innovation is acknowledged as the leading characteristic of entrepreneurs' activity, which is manifested in the emergence and implementation of new socially significant goals, new means of achieving known goals. It is noted that innovation in small and large business is characterized by different mechanisms. Large firms are characterized by entrepreneurial management, focused on organizational transformation and decision-making at all levels of complex hierarchical systems, increasing the resilience and competitive ability of the organization. Decision-making is balanced, risks are assessed and small. For small businesses, innovation is taking the form of more profound change to ensure survival and development - the risks are great and difficult to manage because of limited resources. Because of the differences, we should expect differences in individual-personality characteristics of entrepreneurs of large and small businesses, impacting the success of activities. Empirical research in an explicit form did not reveal the differences between entrepreneurs of small and large businesses, which is reflected in reality small business today provides mainly expansion of the resources of society, the share of innovative enterprises is small, only entrepreneurs with no signs of innovation were affordable - in the fields of trade, communication and small-scale production. The results of the diagnostics of personal characteristics of entrepreneurs and managers confirmed the priority of motivation of achievement in entrepreneurs, manifested in risk-proneness; as well as revealed specifics of intelligence and communication processes, needed for the success of entrepreneurship. However, there are no reasonable grounds to abandon the idea of differentiating entrepreneurship in the form of the implementation of the function of development, as well as the search for the main determinant or systemic determinants of the internal intentions for transformative activity as the main characteristic of entrepreneurs.
\end{abstract}

Keywords: entrepreneurship, the conditions and content of the business activity, personal qualities of successful entrepreneur, achievement motivation, the propensity to risk, intelligence, values, communication. 


\section{References}

Ageev, A. I. (2016). Predprinimatel'stvo [Enterprise] (4th ed.). Moscow: Institute for Economic Strategies/RUBIN. (in Russian)

Aleksandrova, T. L. (2000). Metodologicheskie problemy sotsiologii professiy [Methodological issues of the sociology of professions]. Sotsiologicheskie Issledovaniya, 8, 11-17. (in Russian)

Asaul, A. N. (2009). Organizatsiya predprinimatel'skoi deyatel'nosti [Organization of entrepreneurial activity]. Saint Petersburg: ANO IPEV. (in Russian)

Deyneka, O. S. (2006). Ekonomicheskaya psikhologiya [Economic psychology]. National Psychological Journal, 1(1), 110-113. (in Russian)

Gebert, D., \& von Rosenstiel, L. (2006). Organizatsionnaya psikhologiya. Chelovek i organizatsiya [Organisational psychology: Man and organisation]. Kharkiv: Gumanitarnyi tsentr. (in Russian; transl. of: Gebert, D., \& von Rosenstiel, L. (1992). Organisationspsychologie [Organisational psychology]. Stuttgart/Berlin/Köln: Kohlhammer. (in German))

Hisrich, R., \& Piters, M. (1992). Predprinimatel'stvo, ili Kak zavesti sobstvennoe delo i dobit'sya uspekha [Entrepreneurship, or How to start a business and achieve success]. Moscow: Progres-Univers. (in Russian; transl. of: Hisrich, R. D., \& Piters, M. P. (1989). Entrepreneurship: starting, developing, and managing a new enterprise. Homewood, IL: Irwin.)

Il'in, E. P. (2012). Psikhologiya riska [The psychology of risk]. Saint Petersburg: Piter. (in Russian)

Kabachenko, T. S. (2000). Psikhologiya upravleniya [The psychology of management]. Moscow: Pedagogicheskoe obshchestvo Rossii. (in Russian)

Kotik, M. A. (1989). Psikhologiya i bezopasnost' [Psychology and safety] (3rd ed.). Tallinn: Valgus. (in Russian)

Kuyantsev, I. A., Galachieva, S. V., \& Kuyantseva, I. I. (2012). The role of business in the economic and social development society. Terra Economicus, 10(2, pt. 2), 39-42. (in Russian)

Luk'yanov, A. S. (2002). Psikhologicheskie kachestva predprinimatelya, obespechivayushchie uspeshnost' ego deyatel'nosti [Psychological qualities of entrepreneurs, which ensure success of his activity]. In Psikhologicheskiy resurs v ekonomike i predprinimatel'stve: Materialy Vserossiiskoi nauchniprakticheskoi konferentsii [Psychological resource in economics and entrepreneurship: Proceedings of the All-Russian scientific and practical conference] (pp. 175-182). Stavropol: SeveroKavkazskii Sotsial'nyi Institut/Stavropol'servisshkola. (in Russian)

McClelland, D. (2007). Motivatsiya cheloveka [Human motivation]. Saint Petersburg: Piter. (in Russian; transl. of: McClelland, D. C. (1987). Human motivation. New York: Cambridge University Press.)

Mescon, M. H., Albert, M., \& Khedouri, M. (2017). Osnovy menedzhmenta [Introduction to management]. Moscow: Vil'yams. (in Russian; transl. of: Mescon, M. H., Albert, M., \& Khedouri, M. (1985). Management: individual and organizational effectiveness. New York : Harper \& Row.)

Mukharlyamova, A. U., \& Holuyeva, K. A. (2014). Analysis of the image of the entrepreneur in the modern society. Sovremennye Problemy Nauki i Obrazovaniya, 3, 639-647. (in Russian)

Murray, H. A. (1943). Thematic apperception test. Cambridge, MA: Harvard University Press.

Poznyakov, V. P. (2007). Fenomenologiya predprinimatel'stva: sintez ekonomicheskogo i psikhologicheskogo aspektov [Phenomenology of entrepreneurship: synthesis of economic and psychological aspects]. In D. Ya. Raigorodskii (Ed.), Psikhologiya predprinimatel'stva [The psychology of entrepreneurship] (pp. 3-16). Moscow: Bakhrakh-M. (in Russian)

Romanova, E. S. (2003). 99 populyarnykh professii. Psikhologicheskii analiz i professiogrammy [99 popular professions: psychological analysis and professiograms]. Saint Petersburg: Piter. (in Russian) 
Schumpeter, J. (2008). Teoriya ekonomicheskogo razvitiya [Theory of economic development]. Moscow: Direktmedia Publishing. (in Russian; transl. of: Schumpeter, J. A. (1911). Theorie der wirtschaftlichen Entwicklung [Theory of economic development]. Leipzig: Verlag von Duncker \& Humblot. (in German))

Shcherbatykh, Yu. V. (2008). Psikhologiya predprinimatel'stva i biznesa [The psychology of entrepreneurship and business]. Saint Petersburg: Piter. (in Russian)

Shkaratan, M. O. (1994). Fenomen predprinimatelya: interpretatsiya ponyatii [The phenomenon of entrepreneurship: interpretation of the concept]. In V. V. Radaev (Ed.), Stanovlenie novogo rossiiskogo predprinimatel'stva (social'no-ekonomicheskii aspekt) [The establishment of the new Russian entrepreneurship (a social economic aspect] (pp. 199-247). Moscow: Institute of economics of the RAS. (in Russian)

Strelkov, Yu. K. (2005). Inzhenernaya i professional'naya psikhologiya [Engineering and professional psychology]. Moscow: Akademiya. (in Russian)

Troitskaya, I. V. (2010). Psikhologiya predprinimatel'skoi deyatel'nosti i osnovy ekonomicheskoi psikhologii [Psychology of entrepreneurial activity and the 101 of economic psychology]. Saint Peterburg: SPbGASU. (in Russian)

Tutushkina, M. K. (Ed.). (2001). Prakticheskaya psikhologiya [Applied psychology] (4th ed.). Saint Petersburg: Didaktika Plyus.

Volkov, A. M., Mikadze, Yu. V., \& Solntseva, G. N. (1987). Deyatel'nost': struktura i regulyatsiya [Activity: structure and regulation]. Moscow: Moscow University Press. (in Russian)

Von Mises, L. (2012). Chelovecheskaya dejatel'nost': traktat po ekonomicheskoi teorii [Human activity: A treatise on economic theory]. Chelyabinsk: Sotsium. (in Russian; transl. of: von Mises, L. (1996). Human action: A treatise on economics (4 vols., 4th ed.). Indianapolis, IN: Liberty Fund.)

Zaslavskaya, T. I. (1995). Biznes-sloi rossiiskogo obshchestva: sushchnost', struktura, status [Business layer of the Russian society: essence, structure, status]. Sotsiologicheskie Issledovaniya, 3, 3-12. (in Russian)

Zhuravlev, A. L., \& Poznyakov, V. P. (2012). Sotsial'naya psikhologiya predprinimatel'stva [The social psychology of entrepreneurship]. Moscow: Institute of Psychology of the RAS. (in Russian)

Galina N. Solntseva - associate profeccor, Department of Psychology, Lomonosov Moscow State University, Ph.D.

Research area: structure and regulation of activity, engineering psychology, reflexive processes and management, decision-making.

E-mail: galinasolntseva@mail.ru 